Rev. High Pressure Sci. Technol., Vol. 7 (1998) 1327 1329

\title{
Effect of Stresses on the Growth Thermogram of Yeast
}

\author{
Mitsuo Miyashita and Katsuhiro Tamura \\ Department of Chemical Science and Technology, Faculty of Engineering, The University of Tokushima, \\ Minamijosanjima-cho, Tokushima 770, Japan
}

\begin{abstract}
The metabolic heats of yeast (Saccharomyces cerevisiae) subjected to heat and pressure stresses were measured by differential scanning calorimeter (DSC) in the presence of trehalose. Treatments of high temperature and high pressure inhibited metabolism of the yeast cells. The addition of trehalose retarded the influence of these streses. [trehalose, heat shock, pressure shock, yeast, growth thermogram]
\end{abstract}

\section{Introduction}

Various stresses such as heat, pressure, and chemicals synthesize heat shock proteins in cells, and they acquire resistance to subsequent various stresses that would normally be lethal, a phenomenon called acquired stress tolerance [1]. On the yeast Saccharomyces cerevisiae, it was reported that the heat shock protein hsp104 contributes the acquisition of thermotolerance but another hsps is not necessary for the induction of stress tolerance. Another factor of the induction of stress tolerance is saccharide, especially, disaccharide trehalose. Yeast suspended in medium containing saccharide acquires resistance against following lethal stresses such as high temperature and high pressure. In the presence of sugars, proteins and cell membranes are stabilized thermodynamically $[2,3]$. The most effective sugar is disaccharide trehalose. It is accumulated in the cells when yeast was subjected to moderate heat stress. There is a good correlation between thermotolerance of yeast and the accumulation of trehalose in the cells $[4,5]$. Thus, it is considered that trehalose is used for not only as the energy source but also as the acquisition of stress tolerance in the yeast. Meanwhile, metabolic heats can be used to study quantitatively the biological activities of living cells and tissues. Measuring metabolic heats of yeast cells the effects of various stresses on the growth of the cells were evaluated.

\section{Materials and Methods}

\subsection{Growth conditions of yeast}

The yeast Saccharomyces cerevisiae IFO 10149 was grown at $30^{\circ} \mathrm{C}$ in YPD medium containing $(\mathrm{g} / \mathrm{l})$ glucose, 20 ; polypeptone, 20; yeast extract, 10. Cultures in the logarithmic phase of growth were used. Exponentially growing cells in YPD medium (approx. $10^{7}$ cells $/ \mathrm{ml}$ ) were subjected to a pressure from 0.1 to $125 \mathrm{MPa}$ for 0.5 to $6 \mathrm{~h}$ at $30^{\circ} \mathrm{C}$. Yeast incubated under high pressure for 30 min was exposed to $51^{\circ} \mathrm{C}$ for $10 \mathrm{~min}$. The number of viable cells was measured by counting colonies on YPD agar medium.

\subsection{Measurements of metabolic heats of yeast}

The metabolic heats of yeast were measured using a microcalorimeter (Calorimetry Science Company, DSC 4100 ) at $30^{\circ} \mathrm{C}$ Logarithmic phase cells suspended in YPD medium with 0 to 1.0 $\mathrm{mol} / /$ trehalose were put in the ampoules of the calorimeter (Fig.1). Yeast was incubated according to the following temperature programs in a microcalorimeter: $t^{\circ} \mathrm{C}(30 \mathrm{~min})-51^{\circ} \mathrm{C}(10 \mathrm{~min})-30^{\circ} \mathrm{C}$ (about 2 days), where $t$ is $20,30,43$, or 46 . Cell suspensions in ampoules were pressurized by using $\mathrm{N}_{2}$ gas that was compressed by high pressure pump.

\section{Results}

\subsection{Effects of high pressure on the growth of yeast}

To study the effect of high pressure on yeast, we first evaluated their growth ability and stress tolerance under high hydro-

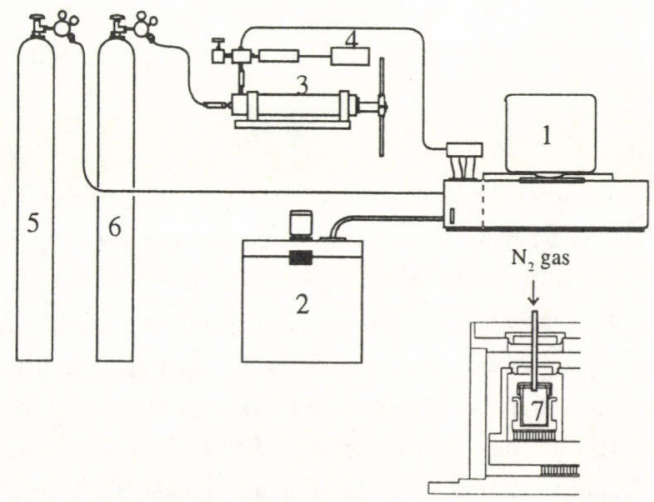

Fig.1. High pressure DSC system.

1. Microcalorimeter (DSC 4100). 2. Cooling bath. 3. High pressure pump. 4. Pressure gauge. 5 and $6 . \mathrm{N}_{2}$ gas bomb. 7. Ampoule cell in DSC. Samples in ampoule were pressurerised using $\mathrm{N}_{2}$ gas compressed by high pressure pump. 


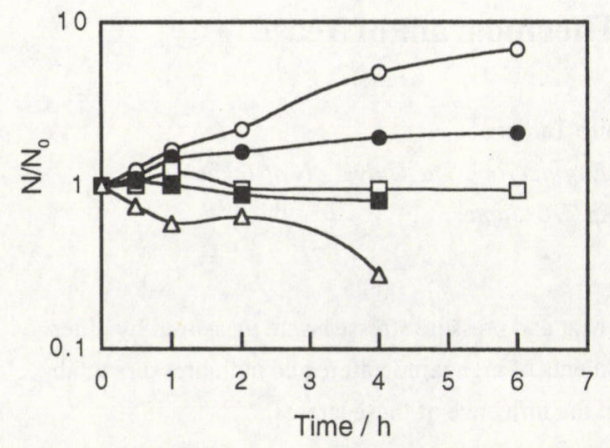

Fig. 2. Growth curve of yeast under high pressure. Yeast cells were incubated for $0-6 \mathrm{~h}$ under $0.1-100 \mathrm{MPa}$ at $30^{\circ} \mathrm{C}$. $\mathrm{N}$, colonies after incubation; $\mathrm{N}_{0}$, colonies before incubation (initial cell number).

\section{○, 0.1 MPa; $25 \mathrm{MPa}$;, $50 \mathrm{MPa} ; \mathbf{n}, 75 \mathrm{MPa}$; $\triangle 100 \mathrm{MPa}$.}

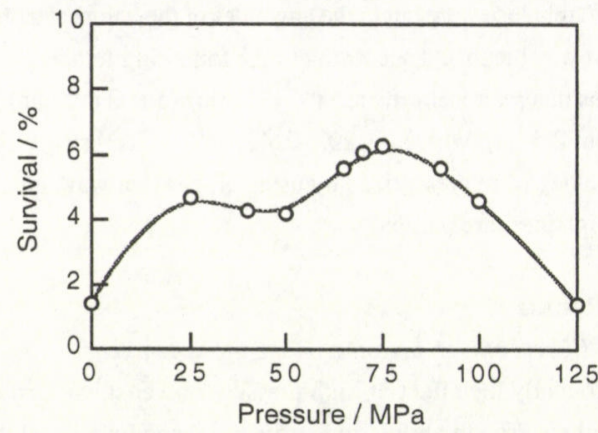

Fig. 3. Thermotolerance of pressure shocked yeast. Yeast incubated for $30 \mathrm{~min}$ at pressures of 0.1 to $125 \mathrm{MPa}$ was subjected to $51^{\circ} \mathrm{C}$ for $10 \mathrm{~min}$. Viable cell numbers were determined by counting colonies on YPD agar medium $[6,7]$.

static pressures. The measurements were carried out by counting colonies on agar. Figure 2 shows the growth curves of yeast incubated under $0.1-100 \mathrm{MPa}$ at $30^{\circ} \mathrm{C}$. Colony forming units (cfu) after incubation was measured at the indicated time then divided by initial cell number. When the yeast was incubated under moderate pressure, their growth was retarded and cfu was decreased with an increase in applied pressure. We could not see any clear difference in cfu of the yeast under $50 \mathrm{MPa}$. Figure 3 shows thermotolerance of yeast incubated under hydrostatic pressure for $30 \mathrm{~min}$. Yeast cells incubated at moderate pressures acquired resistance against high temperature $\left(51^{\circ} \mathrm{C}\right.$ for $\left.10 \mathrm{~min}\right)$. Maximum tolerance was induced in the cells incubated at $75 \mathrm{MPa}$. The survivals then gradually decreased with increasing pressure.

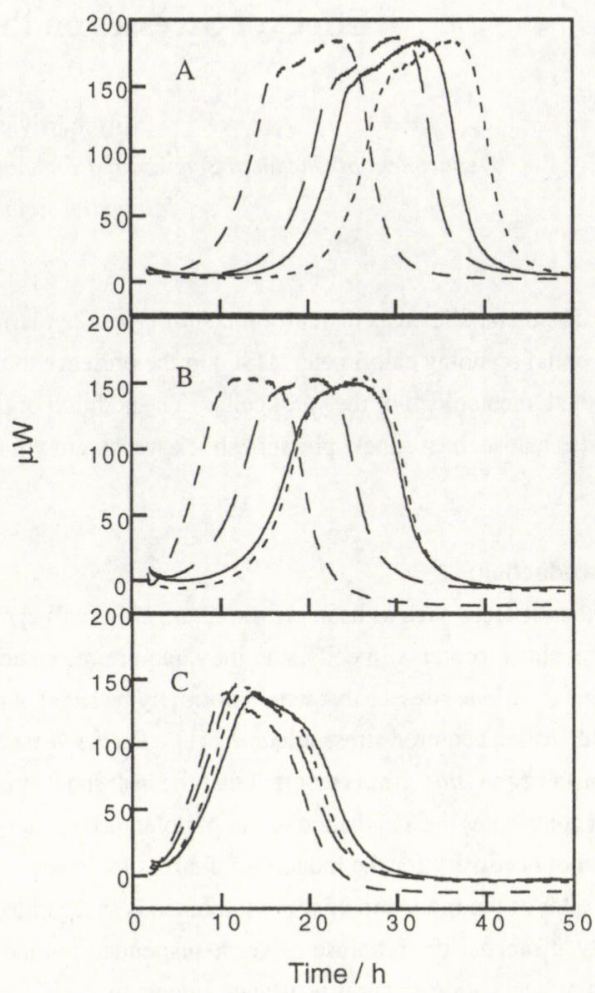

Fig. 4. Growth thermograms of yeast treated for $30 \mathrm{~min}$ at various temperatures. Logarithmic phase cells suspended in YPD medium with and without trehalose were put in the ampoules of the calorimeter. Yeast was incubated according to the following temperature programs in a microcalorimeter: $t^{\circ} \mathrm{C}(30 \mathrm{~min})-51^{\circ} \mathrm{C}(10 \mathrm{~min})-30^{\circ} \mathrm{C}$ (about 2 days), where $t$ is $20,30,43$, or 46 . Trehalose concentration: A, $0 \mathrm{~mol} / l$; B, $0.5 \mathrm{~mol} / l ; \mathrm{C}, 1.0 \mathrm{~mol} / l$.

$\longrightarrow, 20^{\circ} \mathrm{C} ;--, 30^{\circ} \mathrm{C} ;-\cdots, 43^{\circ} \mathrm{C} ; \cdots \cdots, 46^{\circ} \mathrm{C}$.

These results indicate that moderate pressure affects as a stress on yeast, induces stress response in the cells, and inhibit further growth of yeast.

\subsection{Thermograms of yeast incubated under stressed conditions}

Saccharides, especially disaccharide trehalose, induce stress tolerance in yeast cells. Protection effects against high temperature and high pressure is very similar [8]. Thus, we estimated the metabolic heat of yeast subjected to high temperature stress with or without trehalose. The growth thermogram of yeast treated at $30^{\circ} \mathrm{C}$ in Fig.4(A) is taken as a control, because this is the optimum temperature to the growth of yeast. Compared to the con- 


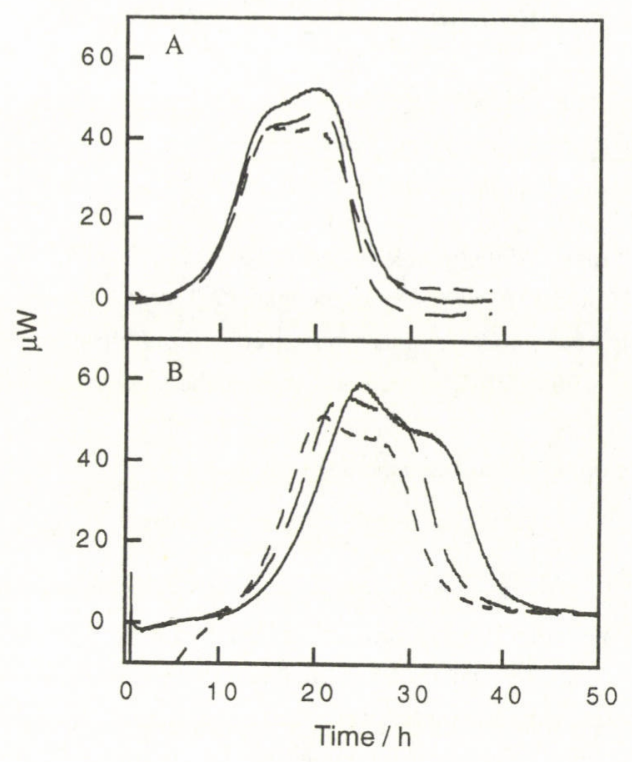

Fig. 5. Growth thermograms of yeast at 0.1 and $5 \mathrm{MPa}$. The metabolic heats of yeast incubated under 0.1 (A) or 5 $\mathrm{MPa}(\mathrm{B})$ with and without trehalose were measured. Trehalose concentration: ——, $0 \mathrm{~mol} / l ;--, 0.5 \mathrm{~mol} / l$; - - - $1.0 \mathrm{~mol} / \mathrm{l}$.

trol, the profile of $43^{\circ} \mathrm{C}$ showed earlier exothermic response. This means that the yeast subjected to $43^{\circ} \mathrm{C}$ for $30 \mathrm{~min}$ acquired thermotolerance and were not affected by subsequent heat stress. On the other hand, other pre-heat shock treatments $\left(20\right.$ and $\left.46^{\circ} \mathrm{C}\right)$ reduced the ability to survive in the following high temperature condition $\left(51^{\circ} \mathrm{C}, 10 \mathrm{~min}\right)$. The addition of trehalose apparently induced thermotolerance to the yeast. The addition of trehalose to medium led the metabolic heat to start at earlier time on the yeast subjected to high temperature. In the presence of $1.0 \mathrm{~mol} / \mathrm{l}$ trehalose, we could not see remarkable effects of pre-heat treatment on the thermogram. These results indicate that trehalose plays an important role to retard the influence of subsequent high temperature stress. Figure 5 shows the effect of trehalose on the growth of yeast incubated at pressures of $0.1 \mathrm{MPa}(\mathrm{A})$ and $5 \mathrm{MPa}$ (B). Pressure apparently retarded the growth rates of yeast. When the yeast was incubated with trehalose at $0.1 \mathrm{MPa}$, the metabolic heat of yeast was slightly reduced but the profile was almost same whether with or without trehalose. We could not see any remarkable changes in the thermograms of yeast incubated with 0 to 1.0 $\mathrm{mol} / \mathrm{l}$ trehalose at atmospheric pressure. However, the addition of trehalose to the medium shifted the thermograms to left (shorter time side) at $5 \mathrm{MPa}$, and broadened their profiles. Namely, trehalose plays a role to compensate the effects of pressure. These results suggest that the addition of trehalose in the medium protect yeast cells from subsequent various stresses. It was found that the metabolic heat can be used as a useful tool for the evaluation of the effect of environmental stresses such as high temperature or high pressure on yeast.

\section{References}

[1] H. Iwahashi, S. C. Kaul, K. Obuchi, and Y. Komatsu, FEMS Microbiol. Lett., 80, 325 (1991).

[2] J. F. Back, D. Oakenfull, and M. B. Smith, Biochem., 18 (23), 5191 (1979).

[3] J. H. Crowe, L. M. Crowe, J. F. Carpenter, and C. A. Wistrom, Biochem. J., 242, 1 (1987).

[4] C. De Virgilio, P. Piper, T. Boller, and A. Wiemken, FEBS., 288, 86 (1991).

[5] T. Hottiger, C. De Virgilio, M. N. Hall, T. Boller, and A. Wiemeken, Eur. J. Biochem., 219, 187 (1994).

[6] M. Miyashita, K. Tamura, and H. Iwahashi, Progress in Anesthetic Mechanism, 3, Special Issue, 422 (1995).

[7] M. Miyashita, K. Tamura, and H. Iwahashi, High Pressure Bioscience and Biotechnology, Progress in Biotechnology Vol. 13, R. Hayashi and C. Balny Eds, Elsevier, 1996, pp.101.

[8] S. Fujii, K. Obuchi, H. Iwahashi, T. Fujii, and Y. Komatsu, Biosci. Biotec. Biochem., 30, 476 (1996). 